\title{
Catastrophic complication of ingestion of corrosive substance
}

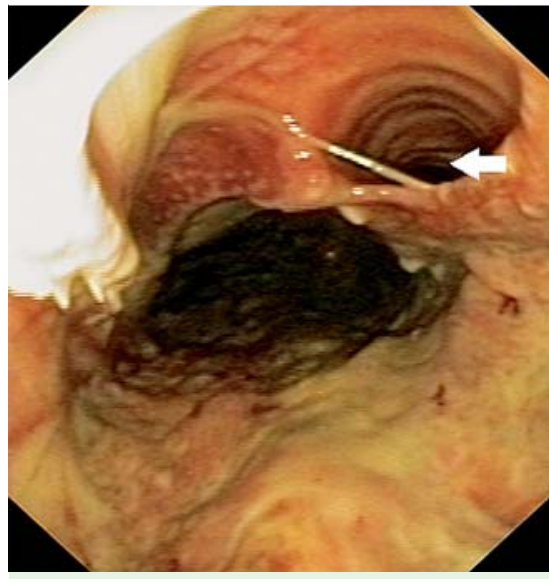

Fig. 1 Endoscopy shows necrosis of the upper esophageal and tracheal wall, with the right bronchus being seen (arrow), in a patient who had ingested lye 7 days previously.

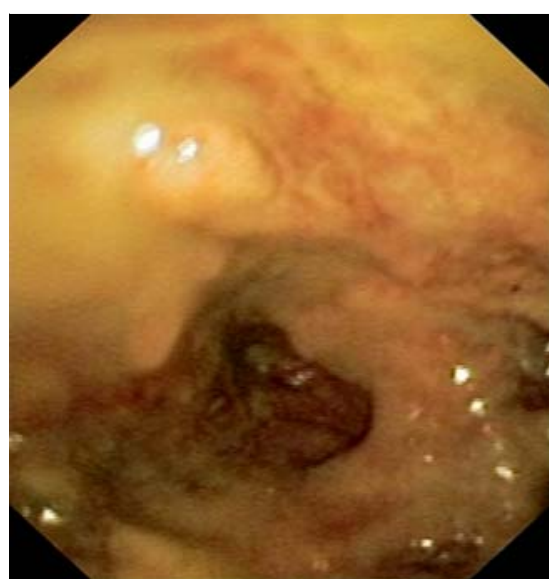

Fig. 3 The lower esophagus is completely necrosed with no identifiable anatomical landmarks, as a result of ingestion of lye.

A 35-year-old man presented 7 days after ingestion of lye with symptoms of complete dysphagia, odynophagia, drooling of saliva, and cough. He had taken lye in a fit of rage, and this was followed by the onset of these symptoms. He had tachypnea, tachycardia, and bilateral crackles in the chest. He was referred to us for insertion of a nasojejunal tube for enteral feeding. Upper gastrointestinal endoscopy revealed complete necrosis of the anterior wall of the upper esophagus and the posterior tracheal wall and both the bronchi were visualized from the esophagus ( $\bullet$ Fig. 1 and $\bullet$ Fig. 2). The lower esopha-

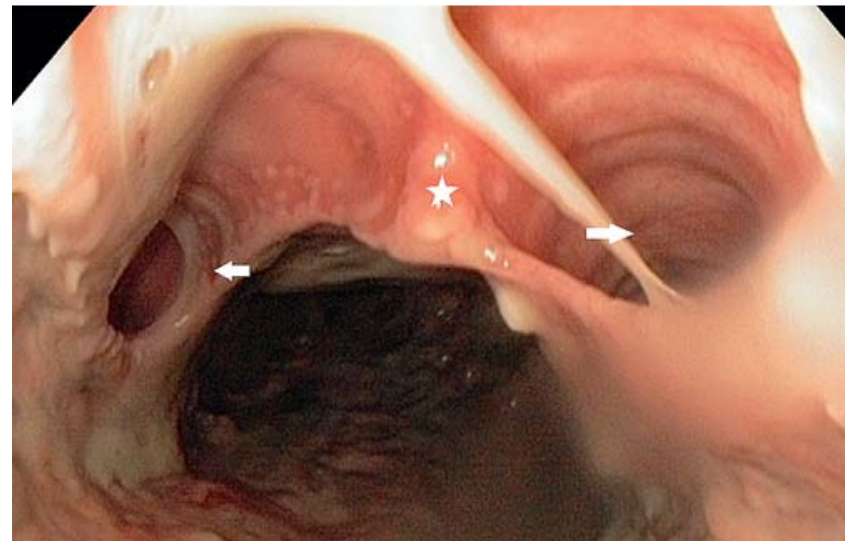

Fig. 2 Both the right and left bronchus (arrows) and the carina $\left({ }^{*}\right)$ seen from the esophagus in a patient who had ingested lye 7 days previously.

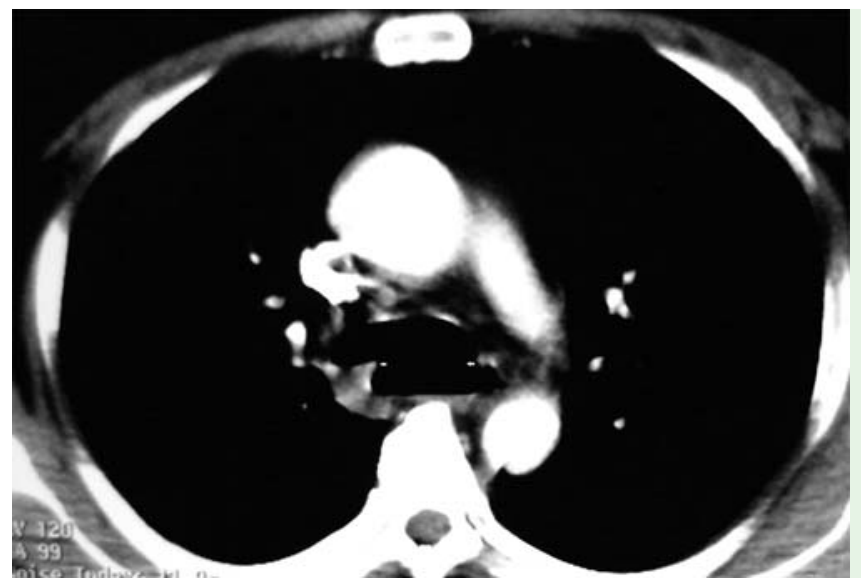

Fig. 4 Computed tomography (CT) shows communication between the trachea and esophagus (arrows) at the level of the carina, in a patient who had ingested lye.

gus was completely necrosed and no definite opening into the stomach could be identified ( Fig.3). Subsequent computed tomography (CT) of the chest confirmed communication between the trachea and esophagus at the level of the carina ( $\bullet$ Fig.4). The patient was subsequently scheduled to undergo a feeding jejunostomy but developed pneumonia and succumbed to progressive sepsis.

Ingestion of corrosives is a common cause of esophagogastric injury. It may result in varying degrees of esophageal damage ranging from erythema, edema of the mucosa, ulceration, hemorrhage, and varying degrees of necrosis to transmural necrosis resulting in perforation. However complete necrosis of the esophagus and the trachea is unusual. Since alkalis are odourless and tasteless they may be ingested in larger amounts than acids and the resulting liquefactive necrosis results in a higher degree of esophageal injury [1]. A previous report has described a similar injury that was visualized on bronchoscopy done for evaluation of hemoptysis, at 1 week after ingestion of an unknown caustic substance [2]. Esophageal perforation can occur at an early stage but is usually apparent a few days after ingestion. Full-thickness necrosis of the esophagus portends a dismal prognosis and warrants surgical management [1].

Endoscopy_UCTN_Code_CCL_1AB_2AC_3AH

Competing interests: None

Vishal Sharma, Surinder S. Rana, Puneet Chhabra, Yalaka R. Reddy, Deepak K. Bhasin

Department of Gastroenterology, Postgraduate Institute of Medical Education and Research (PGIMER), Chandigarh, India 


\section{References}

1 Lahoti D, Broor SL. Corrosive injury to the upper gastrointestinal tract. Indian J Gastroenterol 1993; 12: 135-141

2 Chen $\mathrm{KC}$, Hsiao $\mathrm{CH}$. Tracheal perforation in esophageal corrosive injury. Ann Thorac Surg 2013; 96: 1879

\section{Bibliography}

Dol http://dx.doi.org/

10.1055/s-0034-1365821

Endoscopy 2014; 46: E299-E300

(C) Georg Thieme Verlag KG

Stuttgart · New York

ISSN 0013-726X
Corresponding author

Surinder S. Rana, MD

Department of Gastroenterology PGIMER

Chandigarh 160012

India

Fax: +91-172-2744401

drsurinderrana@yahoo.co.in 